\title{
THREE-DIMENSIONAL SIMULATION OF HIGH REYNOLDS TURBULENT FLOWS IN A RECTANGULAR OPEN CHANNEL WITH THE PRESENCE OF A DISRUPTIVE ELEMENT (OBSTACLES) TRANSVERSELY
}

\author{
$\mathrm{H}^{\prime}$ ssine BOUDIAF ${ }^{1 *}$, Ali FOURAR ${ }^{1}$, Fawaz MASSOUH ${ }^{2}$
}

\begin{abstract}
This study aims at describing a three-dimensional simulation of a turbulent flow with a high Reynolds number in a rectangular open channel with the presence of a disruptive element (obstacles) transversely. The numerical study is based on measuring the flow velocity in two directions, i.e., horizontal and vertical, in four planes located near the obstacle built across a simulated channel. For the modeling of the free surface, a Volume Of Fluid (VOF) multiphase flow model is used. In the present case, namely a study of turbulence, three numerical models are compared, a k- $\varepsilon$ standard, a $k$-w standard and a Reynolds Stress Model (RSM). The verification of the simulation results has allowed us to show the advantages of the Reynolds stress model. This model is more representative of the phenomena of an intense vortex flow in the presence of obstacles, especially in drainage systems.
\end{abstract}

\section{MATHEMATICAL EQUATIONS}

\subsection{Introduction}

In many situations in industry or discharge channels, it is necessary to transfer fluids in highly varied proportions or a component present in two phases is pulsing in a turbulent flow. It is an unfortunate fact that no single turbulence model is universally accepted as being superior for all classes of problems, which led us to confront them with an experimental study conducted in parallel. This would be desirable, but as it could not be done by us because of a lack of equipment, it was decided to conduct an experiment that had already been done by the Laboratory of Fluid Mechanics, INSA, Lyon, France. An experimental study of a flow around an obstacle was designated as the "Ecoulement au tour d'un obstacle, experimentation en canal » (Sajjad, 2001). The Reynolds-Averaged Navier-Stokes (RANS) equations represent transport equations for mean flow quantities only, with all the scales of the turbulence being modeled. The

\section{Address}

1 Department of Hydraulics - Institute of Civil Engineering, Hydraulics and Architecture, Batna University, Street of Chahid Boukhlouf Med El Hadi, CP 05000 - Batna, Algeria

2 École Nationale des Arts et Métiers (ENSAM) Paris, France

Corresponding author: boudiafhcine@yahoo.fr

\section{Key words}

- Turbulent flow,

- high Reynolds number,

- numerical models,

- multiphase flow,

- vortex. 




tion $\left(l_{\text {channel }}=1200 \mathrm{~mm} ; H=400 \mathrm{~mm}\right)$ was built for these experiments; the walls of the measuring section of a $2 \mathrm{~m}$ length are in transparent PVC, with a standard roughness coefficient of $k_{s}=0.0001 \mathrm{~m}$.

To demonstrate the influence of an obstacle, a rectangle emerged with a thickness of $20 \mathrm{~mm}$, a depth of $200 \mathrm{~mm}$, and a width of $400 \mathrm{~mm}$, which was placed against one of the side walls, $260 \mathrm{~cm}$ downstream of the threshold.

The velocities were studied in a plane along $y=110 \mathrm{~mm}$ from the bottom of the channel in a region located $300 \mathrm{~mm}$ upstream and $600 \mathrm{~mm}$ downstream of the obstacle on the lines $(z 1=200 \mathrm{~mm}, z 2=400 \mathrm{~mm}$, $z 3=600 \mathrm{~mm}, z 4=1000 \mathrm{~mm}$ ). The approach adopted for the measurement was $50 \mathrm{~mm}$ along the transverse axis and the longitudinal axis. These experiments were conducted with a flow rate of $72 \mathrm{l} / \mathrm{s}$ (Sajjad, 2001).

\subsection{Mathematical Model}

\subsubsection{Navier-Stokes equations}

Consider a Newtonian fluid of density $\rho$ and kinematic viscosity $v$. The velocity field $\widetilde{U}(x, t)$ of the flow and the fluid are incompressible. Concerning the volume forces, our interest was directed to flows in small areas (channels); the rotational Coriolis forces and centrifugal were ignored before the force of the gravity. The Navier-Stokes equations can be written as:

$$
\begin{gathered}
\frac{\partial \widetilde{U}_{i}}{\partial t}+\frac{\partial}{\partial x_{j}}\left(\widetilde{U}_{i} \widetilde{U}_{j}\right)=-\frac{1}{\rho} \frac{\partial \widetilde{P}}{\partial x_{i}}+\frac{\partial}{\partial x_{j}}\left[v\left(\frac{\partial \widetilde{U}_{i}}{\partial x_{j}}+\frac{\partial \widetilde{U}_{j}}{\partial x_{i}}\right)\right]+g_{i}, \\
\frac{\partial \widetilde{U}_{j}}{\partial x_{j}}=0 .
\end{gathered}
$$

\subsubsection{Turbulence Models}

In a turbulent flow, speeds, pressures, temperatures and other scalar fields experiencing such temporal fluctuations were chosen by us 
to apprehend these variables in a statistical manner so that only the mean values eventually interested us, in terms of their application in the study of turbulence.

In this context, the statistical approach used is based on the classical Reynolds decomposition: each instantaneous field $\Phi$ is considered to be the sum of a mean field $\Phi$ and a random field fluctuation around the mean field $\varphi$.

For this, we introduce two time scales: one is macroscopic $t$, corresponding to the average values, and the other is microscopic $t^{\prime}$, corresponding to the turbulent fluctuations.

$$
\widetilde{\Phi}\left(t, t^{\prime}\right)=\Phi(t)+\varphi\left(t^{\prime}\right)
$$

The mean value is defined by the relation:

$$
\Phi(t)=\frac{1}{\delta t} \int_{0}^{\delta t} \widetilde{\Phi}(t, v) d v
$$

where $\delta t$ is a time differential filter of the turbulent motions.

Note that, according to the definition, the mean value of the fluctuations is zero.

For the variables in which we are interested, this decomposition results in a given moment by the following relations:

$$
\begin{aligned}
& \widetilde{U}_{i}=U_{i}+u_{i} \\
& \tilde{P}=P+p \\
& \widetilde{U}_{i} \widetilde{U}_{j}=U_{i} U_{j}+\overline{u_{\imath} u_{j}} .
\end{aligned} .
$$

$U_{i}, P$ are the mean components and $u_{i}, p$ the fluctuating components; the ensemble average of the product can be divided into two terms.

By applying the decomposition of the Reynolds equation (1), and then by means of the resulting equations, we will now have to solve the following system of equations (Reynolds-averaged):

$\frac{\partial}{\partial t}\left(U_{i}\right)+\frac{\partial}{\partial x_{j}}\left(U_{i} U_{j}\right)=-\frac{1}{\rho_{01}} \frac{\partial P}{\partial x_{i}}+\frac{\partial}{\partial x_{j}}[v\left(\frac{\partial U_{i}}{\partial x_{j}}+\frac{\partial U_{j}}{\partial x_{i}}\right)-\underbrace{\overline{u_{\imath} u_{j}}}_{\text {to modelize }}]+g_{i}$

The occurrence of these correlations is a problem of the closure system of the equations; the number of unknowns exceeds the number of equations. The objective of all the turbulence models is to estimate what kind of terms use a reduced number of new unknowns and the corresponding equations.

\section{- Equations for the $k-\varepsilon$ model:}

The $k-\varepsilon$ standard model is the simplest of complete models with two equations. This model assumes that the turbulence regime is fully established throughout the area and that the effects of the molecular viscosity are negligible compared to the turbulent viscosity (away from walls).

The model calculates the turbulent viscosity involving the kinetic energy of turbulence and the rate of dissipation of the turbulence of the kinetic energy as follows (Keller and Rodi, 1988):

$$
\begin{gathered}
\mu_{t}=C_{\mu} \rho \frac{k^{2}}{\varepsilon}, \\
\frac{\partial(\rho k)}{\partial t}+\frac{\partial}{\partial x_{i}}\left(\rho k U_{i}\right)=\frac{\partial}{\partial x_{j}}\left(\frac{\mu_{t}}{\sigma_{k}} \frac{\partial k}{\partial x_{j}}\right)+\mu_{t}\left(\frac{\partial U_{i}}{\partial x_{j}}+\frac{\partial U_{j}}{\partial x_{i}}\right) \frac{\partial U_{i}}{\partial x_{j}}-\rho \varepsilon \\
\frac{\partial(\rho \varepsilon)}{\partial t}+\frac{\partial\left(\rho U_{j} \varepsilon\right)}{\partial x_{j}}=\frac{\partial}{\partial x_{j}}\left(\frac{\mu_{t}}{\sigma_{\varepsilon}} \frac{\partial \varepsilon}{\partial x_{j}}\right)+C_{\varepsilon 1} \mu_{t}\left(\frac{\partial U_{i}}{\partial x_{j}}+\frac{\partial U_{j}}{\partial x_{i}}\right) \frac{\partial U_{i}}{\partial x_{j}} \frac{\varepsilon}{k}-C_{\varepsilon 2} \rho \frac{\varepsilon^{2}}{k} \\
C_{\mu}=0.09 ; C_{\varepsilon 1}=1.44 ; C_{\varepsilon 2}=1.92 ; \sigma_{k}=1 ; \sigma_{\varepsilon}=1.3
\end{gathered}
$$

\section{- Equations for the $k$ - $w$ model:}

The $k-w$ standard model proposed by the ANSYS FLUENT CFD software is based on the model of Wilcox (1998). Its structure is similar to that of the $k-\varepsilon$ model. This model involves two transport equations, one for the turbulent kinetic energy $k$ and the other for the specific dissipation rate $w$, whose definition is $w=\varepsilon / k$ (Wilcox, 1998):

$$
\mu_{t}=\alpha^{*} \frac{\rho k}{w},
$$

where $\alpha^{*}=\alpha_{\infty}^{*}\left(\frac{\alpha_{0}^{*}+\mathrm{R}_{e t} / R_{k}}{1+\mathrm{R}_{e t} / R_{k}}\right)$ et $\alpha=\frac{\alpha_{\infty}}{\alpha^{*}}\left(\frac{\alpha_{0}+\mathrm{R}_{e t} / R_{w}}{1+\mathrm{R}_{e t} / R_{w}}\right)$,

with $R_{e t}=\frac{\rho k}{\mu w} ; R_{k}=6 ; R_{w}=2.95 . \alpha^{*} ; \alpha_{0}^{*}=\frac{\beta_{i}}{3} ; \beta_{i}=0.072$,

$\frac{\partial}{\partial t}(\rho k)+\frac{\partial}{\partial x_{i}}\left(\rho k U_{i}\right)=\frac{\partial}{\partial x_{j}}\left(\left(\mu+\frac{\mu_{t}}{\sigma_{k}}\right) \frac{\partial k}{\partial x_{j}}\right)+\mu_{t}\left(\frac{\partial U_{i}}{\partial x_{j}}+\frac{\partial U_{j}}{\partial x_{i}}\right) \frac{\partial U_{i}}{\partial x_{j}}-Y_{\text {Dissipation of } k}+S_{k},(17$

$$
\frac{\partial}{\partial t}(\rho w)+\frac{\partial}{\partial x_{i}}\left(\rho w U_{i}\right)=\frac{\partial}{\partial x_{j}}\left(\left(\mu+\frac{\mu_{t}}{\sigma_{\omega}}\right) \frac{\partial w}{\partial x_{j}}\right)+\alpha \frac{w}{k} \mu_{t}\left(\frac{\partial U_{i}}{\partial x_{j}}+\frac{\partial U_{j}}{\partial x_{i}}\right) \frac{\partial U_{i}}{\partial x_{j}}-Y_{w}+S_{w}
$$

\section{- Second-order models: Reynolds Stress Model (RSM)}

The Reynolds Stress Model (RSM) is a second-order closure model. Transport equations are then established for the Reynolds stresses, $\rho \overline{u_{l} u_{J}}$. This model is potentially the most general and the most complete model of classical turbulence. The calculations are satisfactory for many simple flows and more complex ones including jets with impact, and flows in a non-circular conduit, but it is very expensive in the terms of computer usage. The transport equations of the Reynolds stress model in the ANSYS FLUENT CFD software are written in the following form:

$$
\begin{aligned}
& \frac{\partial}{\partial t}\left(\rho \overline{u_{i} u_{j}}\right)+\underbrace{\frac{\partial}{\partial x_{k}}\left(\rho U_{k} \overline{u_{i} u_{j}}\right)}_{C_{i j} \equiv \text { Convection }}=\underbrace{-\frac{\partial}{\partial x_{k}}\left[\rho \overline{u_{i} u_{j} u_{k}}+\overline{p\left(\delta_{k j} u_{i}+\delta_{i k} u_{j}\right)}\right]}_{D_{T, j i} \equiv=\text { Turbulent Diffusion }} \\
& +\underbrace{\frac{\partial}{\partial x_{k}}\left[\mu \frac{\partial}{\partial x_{k}}\left(\overline{u_{i} u_{j}}\right)\right]}_{D_{L i j}=\text { Molecular Diffusion }} \underbrace{-\rho\left(\overline{u_{i} u_{k}} \frac{\partial U_{j}}{\partial x_{k}}+\overline{u_{j} u_{k}} \frac{\partial U_{i}}{\partial x_{k}}\right)}_{P_{i j} \equiv \text { Stress production }} \underbrace{-\rho \beta\left(g_{i} \overline{u_{j} \theta}+g_{j} \overline{u_{i}} \theta\right)}_{G_{i j} \equiv \text { Buoyancy production }} \\
& +\underbrace{p\left(\frac{\partial u_{i}}{\partial x_{j}}+\frac{\partial u_{j}}{\partial x_{i}}\right)}_{\phi_{i j}=\text { pression strain }}-\underbrace{2 \mu \frac{\partial u_{i}}{\partial x_{k}} \frac{\partial u_{j}}{\partial x_{k}}}_{\varepsilon_{i j} \equiv \text { Dissipation }} \underbrace{-2 \rho \Omega_{k}\left(\overline{u_{j} u_{m}} \varepsilon_{i k m}+\overline{u_{i} u_{m}} \varepsilon_{j k m}\right)}_{F_{i j}=\text { Production by system rotation }}+\underbrace{S}_{\text {Source term }}
\end{aligned}
$$

\section{NUMERICAL METHODS OF THE RESOLUTION}

\subsection{Construction of the mesh}

The channel has a fairly simple geometry. A structured 3D hexahedral mesh was put into use. We can easily decrease the size of the cells in the desired areas (areas with a high gradient, close to the walls or obstacle). To limit the total number of cells along the $x$ axis in regions where the flow is undisturbed (a small gradient of the velocity) upstream of the obstacle, the mesh size is decreasing from 20 to $2 \mathrm{~cm}$; in the zones downstream of the obstacle, the mesh size is increasing from 2 to $10 \mathrm{~cm}$, depending on the $y$ and $z$ axes, considering a constant cell size of $2 \times 1 \mathrm{~cm}$ (Fig. 3); the cells are clamped at the free surface near the obstacle and near the bottom. The number of nodes obtained is 103,200 nodes. 


\subsection{Presentation of the mesh in GAMBIT software}

\subsubsection{Creating the Geometry and Mesh of the Walls}

This type of mesh is used to locally refine the mesh in areas near the walls and obstacle, because of some important phenomena that develops in the volume.
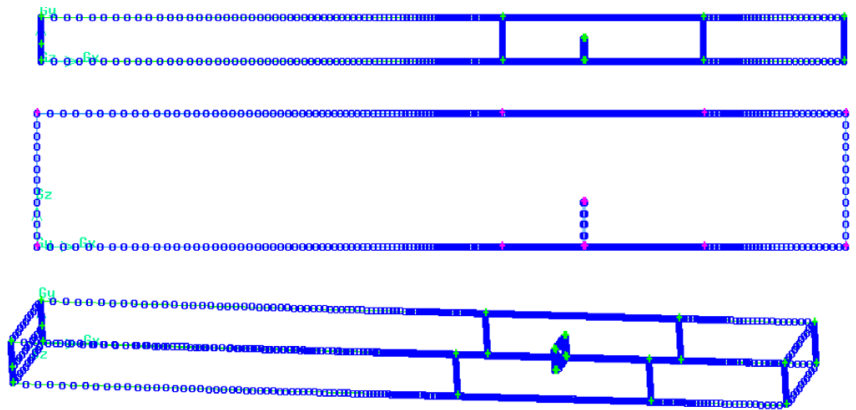

Fig. 2 Mesh of the walls.

\subsubsection{Mesh Volume}

The volume must be meshed with the GAMBIT software by the use of a standard mesh.

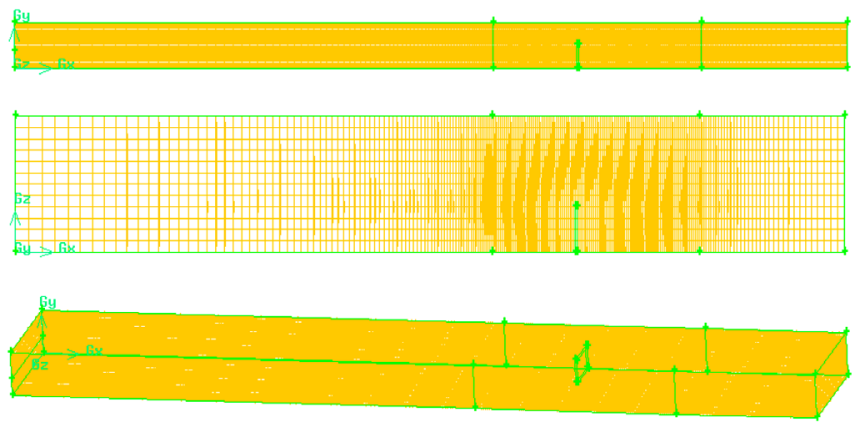

Fig. 3 Mesh volume.

\subsubsection{The boundary conditions}

The declaration of the boundary conditions is an important step for the further calculations to be performed by the ANSYS FLUENT CFD software.

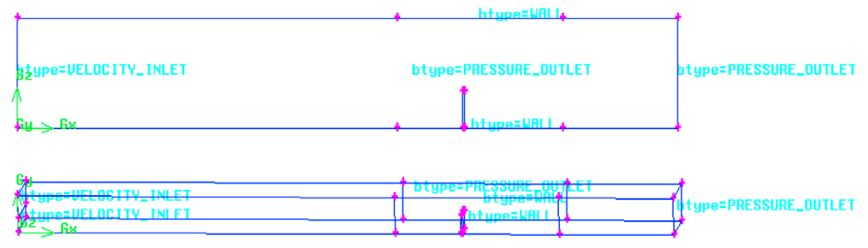

Fig. 4 The boundary conditions.

\subsection{Flow parameters}

See Tab. 1.

\section{RESULTS}

All three turbulence models used for our numerical calculations clearly showed that the presence of the obstacle created major disruptions in the flow (Fig. 5). This is reflected in particular by:

a) The velocities are zero near the side walls and close to the obstacle built across the channel; this is due to the boundary conditions imposed by the declared computer code (Wall type).

b) The emergence of a recirculation zone at a low speed on the order of a few $\mathrm{cm} / \mathrm{s}$, located in alignment with the obstacle and which extends to the end sill, cells with relatively high stationary currents. Taking into account the value of the "length of the attachment" considered as the distance between the obstacle and the point where the rapid flow leaves the wall, and estimated in the literature (Launder and Spalding 1974) as 10 times the width of the obstacle, which is $4 \mathrm{~m}$ in the case of our study, it is not surprising that the recirculation zone extends to the threshold, which is located about $3 \mathrm{~m}$ downstream of the obstacle.

c) The formation of a liquid stream which bypasses the obstacle and then starts to move much more rapidly in the section opposite the obstacle (speeds of the order of a few tens of $\mathrm{cm} / \mathrm{s}$ ).

The very successful results using the ANSYS FLUENT CFD software on the horizontal and vertical profiles of the velocities of the three turbulence models, the RSM, the k- $\varepsilon$ and the k-w, were verified and validated experimentally. Our work achieved different results on the same vertical plane: $\mathrm{z}=200 \mathrm{~mm}$ (Figs. 6 and 10), $\mathrm{z}=400 \mathrm{~mm}$ (Figs. 7 and 11), $\mathrm{z}=600 \mathrm{~mm}$ (Figs. 8 and 12), $\mathrm{z}=1000 \mathrm{~mm}$ (Figs. 9 and 13). (Figs. 6 and 7) and (Figs. 10 and 11) illustrate the profiles of the horizontal and vertical velocities as a function of the position of the $\mathrm{x}$ axis in a zone that passes through the obstacle. The conclusions that can be made are:

In the area upstream of the obstacle:

Our results espouse almost the same shape as the experimental results.

- The horizontal velocity decreases each time we approach the obstacle (Figs. 6 and 7);

- An increase in the vertical velocity whenever we approach the obstacle (Figs. 10 and 11);

- The RSM model gives higher values for the horizontal velocities ;

o The standard k- $\varepsilon$ model gives higher values for the vertical velocities ;

- At the closest obstacle the RSM model provides more suitable results compared to the two other models.

- In the area downstream of the obstacle:

- The RSM and the k-w models give higher values (especially for the horizontal velocities);

- The experimental results have a tendency to be more or less stable in the $\mathrm{x}$ direction; the three models, however, provide an increase in the horizontal velocity and a decrease in the vertical velocity values.

Tab. 1 Flow parameters.

\begin{tabular}{|c|c|c|c|c|c|c|c|c|}
\hline $\begin{array}{c}U_{1} \\
(\mathrm{~m} / \mathrm{s})\end{array}$ & $\begin{array}{c}H_{1} \\
(\mathrm{~m})\end{array}$ & $\begin{array}{c}U_{2} \\
(\mathrm{~m} / \mathrm{s})\end{array}$ & $\begin{array}{c}H_{2} \\
(\mathrm{~m})\end{array}$ & $\begin{array}{c}R e \\
(/)\end{array}$ & $\begin{array}{c}\rho_{01} \\
\left(\mathrm{~kg} / \mathrm{m}^{3}\right)\end{array}$ & $\begin{array}{c}v_{01} \\
\left(\mathrm{~m}^{2} / \mathrm{s}\right)\end{array}$ & $\begin{array}{c}\rho_{\mathbf{0 2}} \\
\left(\mathrm{kg} / \mathrm{m}^{3}\right)\end{array}$ & $\begin{array}{c}v_{02} \\
\left(\mathrm{~m}^{2} / \mathrm{s}\right)\end{array}$ \\
\hline 0.40 & 0.15 & 0.00 & 0.05 & $4.80 \mathrm{E}+5$ & 998.20 & $1.00 \mathrm{E}-6$ & 1.225 & $1.46 \mathrm{E}-5$ \\
\hline
\end{tabular}




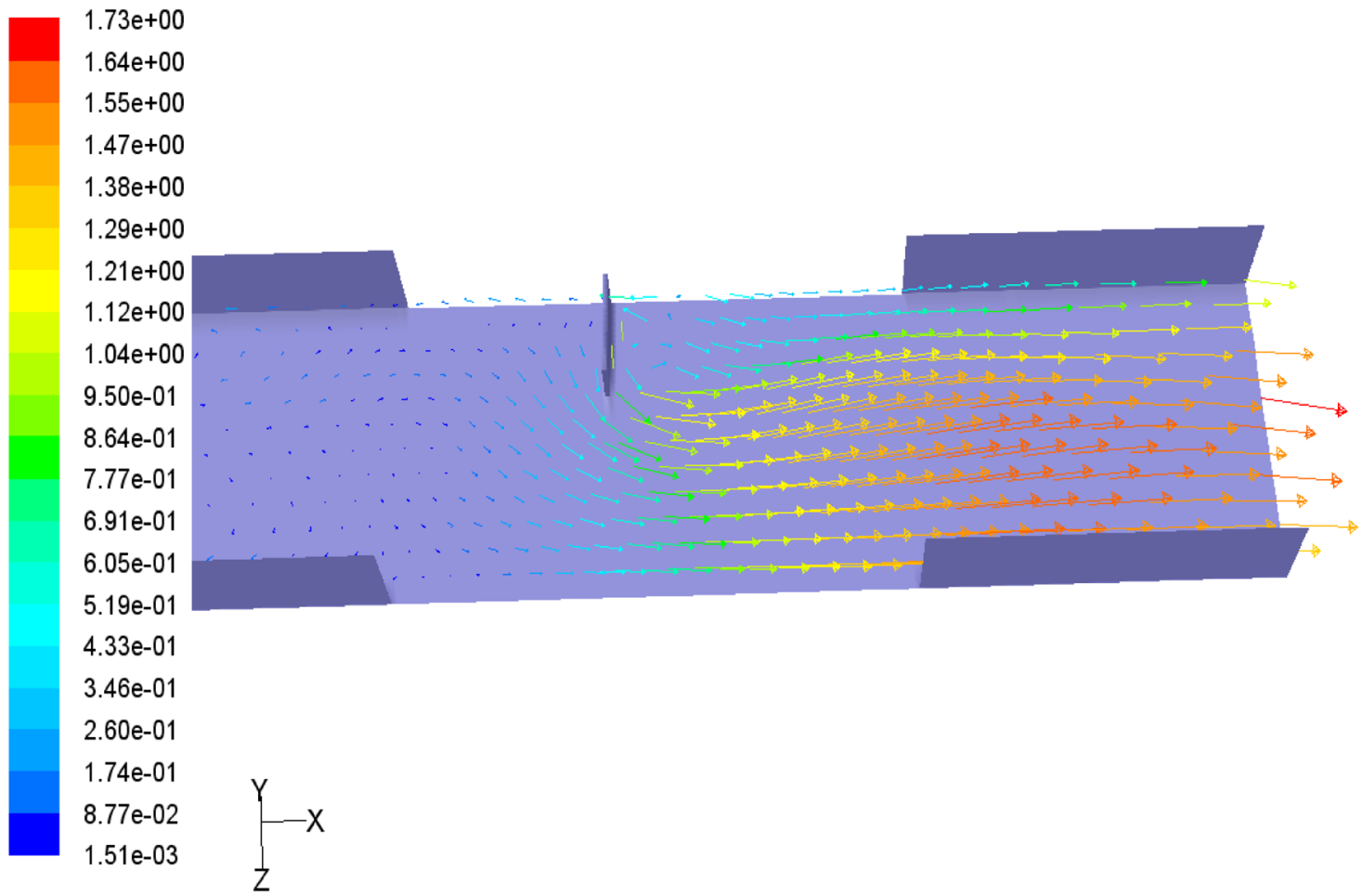

Fig. 5 Velocity $(\mathrm{m} / \mathrm{s})$ calculated by the $k$ - $\varepsilon$ model on a horizontal plane $(y=110 \mathrm{~mm})$.

The (Figs. 8 and 9) and (Figs. 12 and 13) illustrate the profiles of the horizontal and vertical velocities as a function of the position of the $\mathrm{x}$ axis in a zone away from the obstacle. The main points that can be drawn are:

- Our results are in good agreement with the experimental results.

- An increasing horizontal velocity following the position $\mathrm{x}$ and a decreasing vertical velocity always follows the same position $\mathrm{x}$;

- The k-w model gives higher values (horizontal velocity) versus the $\mathrm{k}-\varepsilon$ standard model, which gives higher values in the vertical direction of the velocities ;

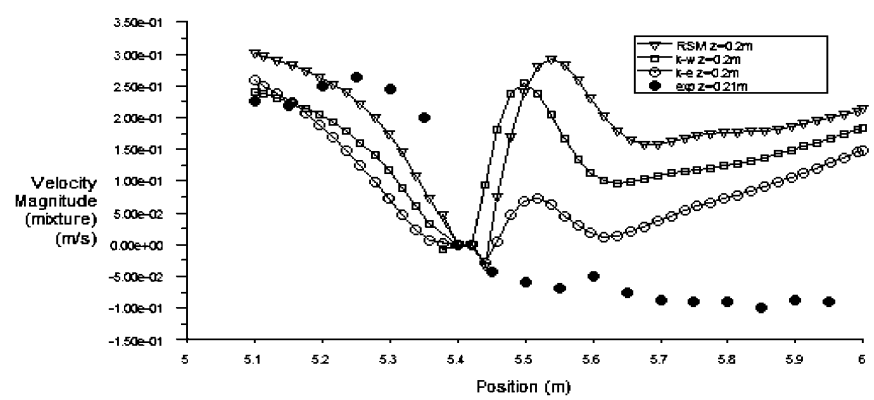

Fig. 6 Horizontal velocity $U(\mathrm{~m} / \mathrm{s})$, on a vertical plane $(z=200 \mathrm{~mm})$.

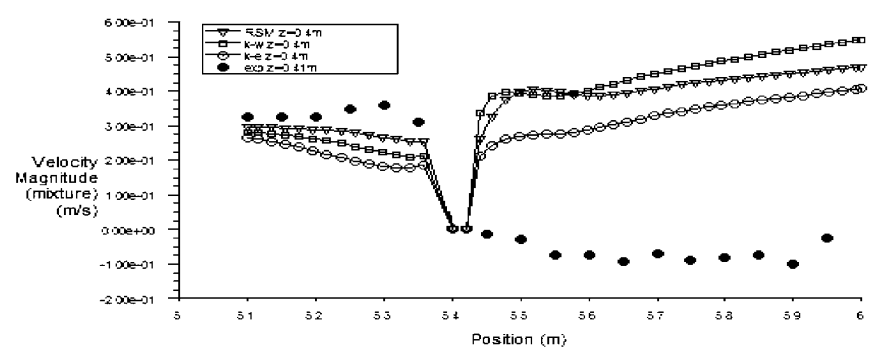

Fig. 7 Horizontal velocity $U(\mathrm{~m} / \mathrm{s})$, on a vertical plane $(z=400 \mathrm{~mm})$.
- In the farthest plane from the obstacle (Fig. 9) we see that both the RSM models and the standard $\mathrm{k}-\varepsilon$ have almost identical manners, compared with the k-w model;

- In the farthest plane from the obstacle, both the RSM and k- $\varepsilon$ standard models produce better results.

In all the figures which follow, the word "position" $三 \mathrm{x}$ axis.

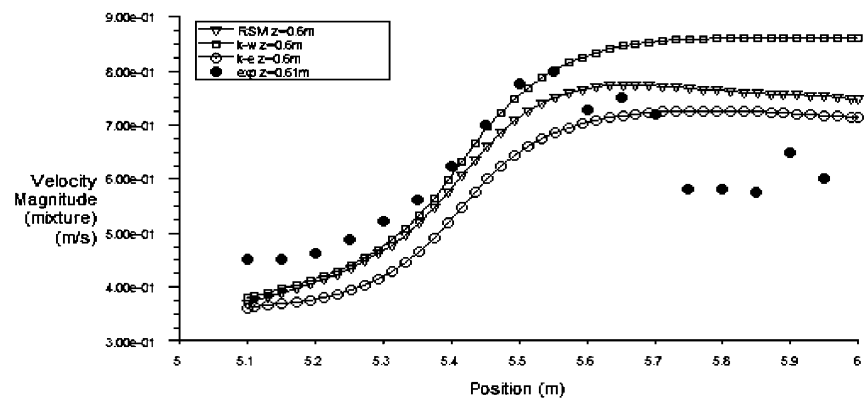

Fig. 8 Horizontal velocity $U(\mathrm{~m} / \mathrm{s})$, on a vertical plane $(z=600 \mathrm{~mm})$.

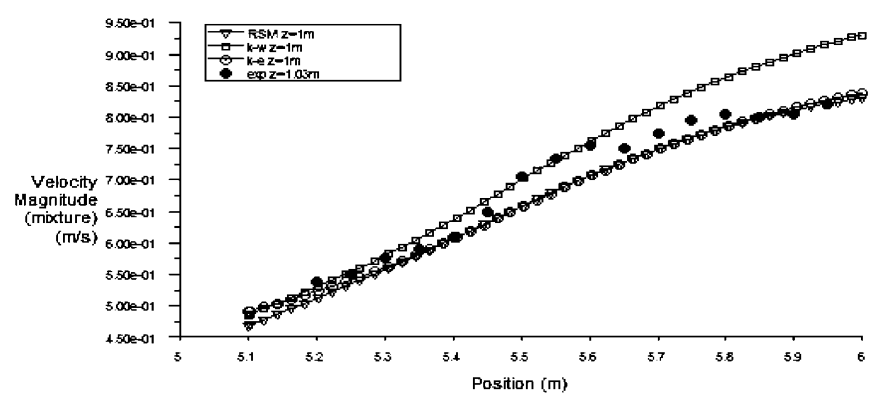

Fig. 9 Horizontal velocity $U(\mathrm{~m} / \mathrm{s})$, on a vertical plane $(z=1000 \mathrm{~mm})$. 


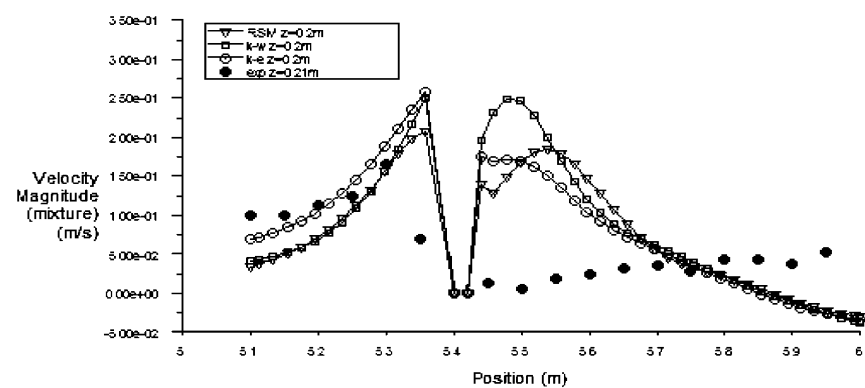

Fig. 10 Vertical velocity $W(\mathrm{~m} / \mathrm{s})$, on a vertical plane $(z=200 \mathrm{~mm})$.

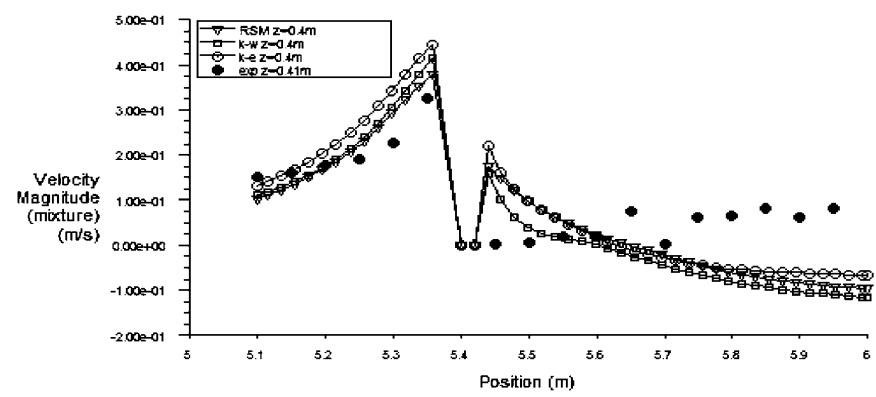

Fig. 11 Vertical velocity $W(\mathrm{~m} / \mathrm{s})$, on a vertical plane $(z=400 \mathrm{~mm})$.

\section{CONCLUSION}

The phenomena observed and the results obtained in this study show that the rate decreases in the horizontal direction each time we approach the transverse obstacle; however, the velocity increases when approaching this obstacle.

In addition, the results of the numerical experiment upstream of the obstacle are in good agreement with the experimental results. Regarding the obstacle near the recirculation zone, the homogeneity of the calculated results is very low compared to the first zone.

While this channel geometry is very simple, the flow that develops is unusually extremely complex.

Using visualizations, flow and spectral analysis (Adams and Johnston, 1988) observed very low frequency beats in the recirculation zone to be very unstable; this instability may have an effect on the values of the Reynolds-average.

Both the RSM and $k-\varepsilon$ models apply when the effects of the molecular viscosity are negligible away from the walls, which is why these models need near-wall treatments for the inner region of the boundary layer; however, the near-wall treatment tends to become less reliable when the flow situations depart too much from the ideal conditions that are assumed in their derivation. Among other things, the constant shear and local equilibrium hypotheses are the ones that most restrict the universality of the near-wall treatment. Accordingly, when the near-wall flows are subjected to severe pressure gradients and when the flows are in a strong non-equilibrium, the quality of the predictions is likely to be compromised,This was studied by (Ruderich and Fernholz, 1986), who also insist on the absence of a classical logarithmic wall law; however, the majority of the models of turbulence use a log-low region so that inaccuracies at the vicinity of the wall can appear; however regarding the $k$ - $w$ model formulated to be applied all through the boundary layer, as long as the resolution of the mesh near the wall is sufficient, but not with a high Reynolds number, as is the case in our study.

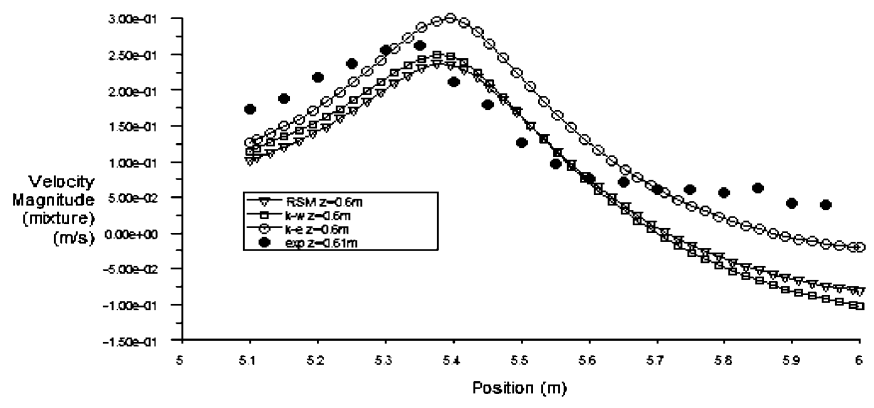

Fig. 12 Vertical velocity $W(\mathrm{~m} / \mathrm{s})$, on a vertical plane $(z=600 \mathrm{~mm})$.

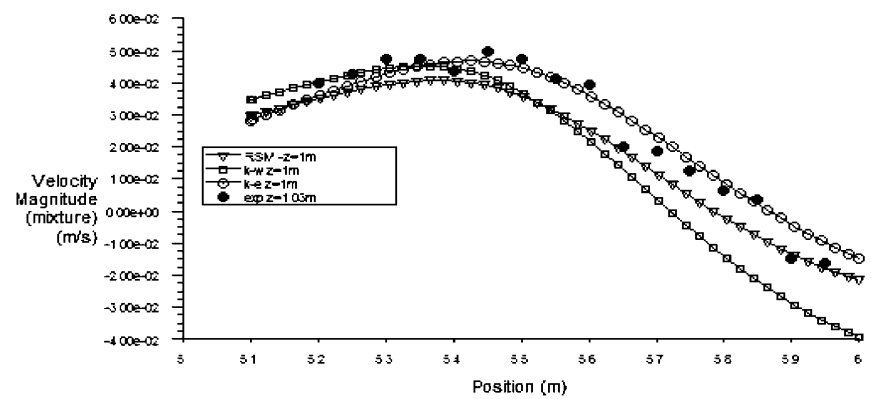

Fig. 13 Vertical velocity $W(\mathrm{~m} / \mathrm{s})$, on a vertical plane $(z=1000 \mathrm{~mm})$.

The more we get away from the obstacle, the more the simulation results are inherently larger than the experimental values.

In summary, it is recommended to study the wall laws, practically in the recirculation zone.

The semi-empirical coefficients used by the models based on the approach (RANS), whose values are taken at times by default are determined experimentally. According to Rodi (1981), these models have a high sensitivity to semi-empirical coefficients; depending on their value, the calculation results may differ.

In areas close to walls, the $k$ - $w$ model formulated to be applied all through the boundary layer gives better results; we believe that the results obtained by the RSM and $k-\varepsilon$ models are virtually identical, in that they use the same treatment of the parietal area (near-wall treatments).In areas away from the walls and the obstacle, the RSM and standard $k-\varepsilon$ model produces better results in contrast to the standard $k$ - $w$ model, which provides poor results, especially in situations such as a flow with a high Reynolds number. Finally, verification of the results allowed us to better capture the advantage of the Reynolds stress model (RSM). 


\section{List of Symbols}

\section{Latin letters}

Symbol Description

$\partial t \quad$ Time differential

$\partial x_{i} \quad$ Space differential

$g \quad$ Gravity acceleration

$H \quad$ Channel height

$K_{S} \quad$ Strickler roughness

$k \quad$ Turbulent kinetic energy

$k_{S} \quad$ absolute roughness

$L_{\text {channel }}$ Channel length

$l_{\text {channel }}$ Channel width

$P$ medium pressure

$p \quad$ Turbulent pressure fluctuation

Re Reynolds number

$r \quad$ volume fraction

$t \quad$ Time

$U \quad$ Medium velocities along the $x$ axis
Symbol Description Unit

$U_{i} \quad$ Medium velocities $\quad(\mathrm{m} / \mathrm{s})$

$u \quad$ Turbulent in the fluctuation velocities along the $x$ axis $(\mathrm{m} / \mathrm{s})$

$u_{i} \quad$ Turbulent in the fluctuation velocities $(\mathrm{m} / \mathrm{s})$

$V^{l} \quad$ Medium velocities along the $y$ axis $\quad(\mathrm{m} / \mathrm{s})$

$W \quad$ Specific dissipation rate $\quad(1 / s)$

$x_{i} \quad$ coordinates

$\left(\mathrm{m} / \mathrm{s}^{2}\right)$

$(m)$

$\left(m^{1 / 3} / s\right)$

$\left(m^{2} / s^{2}\right)$

$(m)$

(m)

$(m)$

$\left(\mathrm{kg} / \mathrm{m} . \mathrm{s}^{2}\right)$

$\left(\mathrm{kg} / \mathrm{m} \cdot \mathrm{s}^{2}\right)$

$(/)$

$(s)$

$(\mathrm{m} / \mathrm{s})$

\section{Greek letters}

Symbol Description Unit

$\varepsilon \quad$ Dissipation rate of the turbulent kinetic energy $\quad\left(\mathrm{m}^{2} / \mathrm{s}^{3}\right)$

$\mu \quad$ Molecular dynamic viscosity $\quad(\mathrm{kg} / \mathrm{m} . \mathrm{s})$

$\mu_{t} \quad$ Turbulent dynamic viscosity $\quad(\mathrm{kg} / \mathrm{m} . \mathrm{s})$

$v \quad$ Kinematic viscosity $\left(\mathrm{m}^{2} / \mathrm{s}\right)$

$v_{t} \quad$ Turbulent kinematic viscosity $\quad\left(\mathrm{m}^{2} / \mathrm{s}\right)$

$\rho^{t} \quad$ Fluid density $\quad\left(\mathrm{kg} / \mathrm{m}^{3}\right)$

$\tau_{p} \quad$ Wall friction $\quad\left(\mathrm{kg} / \mathrm{m} \cdot \mathrm{s}^{2}\right)$

\section{REFERENCES}

Adams, E. W. - Johnston, J. P. (1988) Flow structure in the nearwall zone of a turbulent separated flow. AIAA Journal, Vol. 26, No. 8, pp. 932-939.

Aris, R. (1962) Vectors, tensors and the basic equations of fluid mechanics. Englewood Cliffs, N.J. Prentice-Hall, Inc. reprinted, Dover, New York, 1989.

Delphine, L. - Stéphane, V. - Eric, A. (2005) A numerical experiment on the interaction between a film and a turbulent jet. C. R. Mécanique 333, 343-349.

Drew D.A. (1983) Mathematical modeling of two-phase flow. Ann. Rev. Fluid. Mech., Vol.15, pp. 261-291.

Fluent Inc.Fluent (2003) Tutorial Guide. Vol. 1, 2, 3, 16.

Fluent Inc.Fluent (2003) User's Guide. Vol. 1, 2, 3, 4, 6, 10, 22, 24.

Fluent Inc.Gambit (2001) Modeling Guide.

Franch, R.H. (1986) Open-channel hydraulics. New York, McGraw-Hill, 705 pp.

Hérouin, E. (1991) Modélisation des écoulements complexes à surface libre en milieu naturel (Modeling of complex free surface flows in natural environment). Rapport Cemargef Lyon, 95 pp.

Keller, Rodi, W. (1988) Prediction of flow characteristics in main channel/flood plain flows. Journal of Hydraulic Research, Vol. 26, No. 4, pp. 425-441.

Launder, B. - Spalding, D. (1972) Lectures in mathematical models of turbulence. Academic Press, London, England.

Launder, B. - Spalding, D. (1974) The numerical computation of turbulent flows. Computational methods in applied mechanical engineering, Vol. 3, pp. 269-289.
Launder, B. E. - Reece. G. J. - Rodi, W. (1975) Progress in the development of a Reynolds-stress turbulence closure. J. Fluid Mech., Vol. 68, No. 3, 537-566.

Ouillon, S. - Dartus, D. (1997) Three-dimensional computation of flow around groyne. Journal of Hydraulic Engineering, Vol. 123, No. 11, pp. 962-970.

Patrick, C. (2000) Turbulence en mécanique des fluides, analyse du phénomène en vue de sa modélisation à l'usage de l'ingénieur (turbulence in fluid mechanics, analysis of the phenomenon to its modeling the use of engineering). Éditions cépaduès, Coll. Polytech de l'I.N.P de Toulouse.

Rodi, W. (1981) Turbulence models and their application in hydraulics. AIRH, ed. 1984.

Ruderich, R. - Fernholz, H. (1986) An experimental investigation of a turbulent shear flow with separation, reverse flow, and reattachment. JFM, Vol.163, pp. 283-322.

Sajjad, H. (2001) Contribution à la modélisation d'une inondation en zone urbanisée, approche bidimensionnelle par les équations de Saint Venant (Contribution to the modeling of flooding in urban areas, two-dimensional approach by the Saint Venant equations. Thèse pour obtenir le titre de docteur de l'institut national des sciences appliquées de Lyon spécialité mécanique + annexe, $\mathrm{N}^{\circ}$ d'ordre 01 ISAL 0019.

Wilcox, D. C. (1998) Turbulence modeling for CFD. DCW industries, Inc., La Canada, California. 